\title{
Carbon Capture and Storage: A Challenging Approach for Mitigation of Global Warming
}

\author{
Hai Yu \\ CSIRO Energy Technology, Canberra, Australia \\ Email: hai.yu@csiro.au
}

Received May 20, 2013; revised June 23, 2013; accepted July 1, 2013

Copyright (C) 2013 Hai Yu. This is an open access article distributed under the Creative Commons Attribution License, which permits unrestricted use, distribution, and reproduction in any medium, provided the original work is properly cited.

Carbon dioxide $\left(\mathrm{CO}_{2}\right)$ emitted into the atmosphere by fossil fuel combustion is the most significant greenhouse gas contributing to climate change. Use of coal alone accounts for $43 \%$ of global $\mathrm{CO}_{2}$ emission in 2010 . As the most abundant, the most reliable and cheap energy source, coal will continue to play a significant role in the world's economy and improving people's standard of living in particular in the developing countries. With the strong demand for coal, there is no doubt that the $\mathrm{CO}_{2}$ emissions will continue to rise. On May 9, 2013, the daily mean concentration of carbon dioxide in the atmosphere of Mauna Loa, Hawaii, surpassed 400 ppm for the first time since measurements began in 1958. The rate of increase is ca $2.1 \mathrm{ppm}$ per year during the last 10 years. Without significant reduction of $\mathrm{CO}_{2}$ emissions, it is unlikely to limit the long-term concentration of greenhouse gasses to $450 \mathrm{ppm} \mathrm{CO}_{2}$ by 2050 .

Carbon capture and storage (CCS) is a process $\mathrm{CO}_{2}$ is separated from large point sources, including fossil fuel power plants, and transported to a disposal site, normally an underground geological formation, for permanent storage. It is generally agreed that CCS is the only technology available to make deep cuts in greenhouse gas emissions while still using fossil fuels and much of today's energy infrastructure. According to the International Energy Agency (IEA), CCS will account for 19\% of total emissions reduction if the global $\mathrm{CO}_{2}$ emissions are halved by 2050. However, looking back, there has been great uncertainty surrounding the commercial implementation of CCS technologies. Despite the fact that all the necessary components of CCS process are commercially available, the question about the large scale $\mathrm{CO}_{2}$ storage remains. The progress towards the commercial deployment of CCS technologies is slow.

A number of factors contribute to a slow progress of CCS development. Firstly, the CCS projects are very costly. Most studies estimate that CCS will add more than $50 \%$ to the cost of electricity from coal. The costs for the first commercial CCS plants will be much higher than the following projects. No one wants to take the risk to be the first one. Secondly, CCS depends on the political polices to drive it. There is no a legally binding agreement on the emissions reduction applied to all countries and there is no market for CCS. Last but not the least, CCS depends on the government support. In an unfavourably financial environment, the R \& D spending is expected to decline. Recently Australian government has announced a budget cut of $\$ 500$ million over three years to its national CCS flagship program, almost one third of the total funding from the federal government. The Australia's opposition party has even pledged to abolish the carbon tax if elected in September 2013.

So, what is the future for CCS? It is a difficult question to answer. A critical issue is who is going to pay for the development of CCS. It should be pointed out that the majority of the upcoming projects use captured $\mathrm{CO}_{2}$ for enhanced oil recovery. The reason for that is EOR can facilitate the development of CCS by improving the financial viability of the CCS, building the infrastructure required for CCS, and developing capability along the supply chain. An increase in EOR projects reflexes the importance of $\mathrm{CO}_{2}$ utilisation. Carbon Capture, Utilisation and Storage (CCUS) is gaining increased attention in particular in USA and China. It is unlikely for the developing counties to deploy the CCS technologies with financial support from the government alone. In these countries the priorities are to sustain the economic growth and improve people's living standard. To move CCS forward, it is important to realise the challenges facing the CCS development and make appropriate adjustment based on the political and economic realities. Considering that the funding on the development of CCS is limited, the international R \& D program needs to be well coordinated and have the right focus and the right scale to avoid unproductive overlap between demonstration projects and ensure that limited resources are spent wisely to achieve the highest benefits.

As a researcher working on $\mathrm{CO}_{2}$ capture, I am glad to 
see the increasing number of papers in CCS published in the international journals and more and more submissions come from developing countries. From a research point of view, I think it is important to continue research to further reduce the costs for $\mathrm{CO}_{2}$ capture and risks associated with $\mathrm{CO}_{2}$ storage. It is also important to explore opportunities to utilise the captured $\mathrm{CO}_{2}$ to improve the economic viability of the CCS technologies. The path of technological development has never been easy and straightforward. We may face a few years of slow progress but once the demonstration projects get underway, this will regenerate the interest in CCS or CCUS as a global mitigation option. 